\section{Exposure and affect: A field experiment ${ }^{1}$}

ROBERT B. ZAJONC and D. W. RAJECKI, University of Michigan, Ann Arbor, Mich. 48104

A field experiment was carried out to test the hypothesis that the mere repeated exposure of a stimulus is a sufficient condition for the enhancement of the $S$ 's attitude toward it. The utilization of a series of display advertisements in the newspapers of two universities made it possible to specify that a set of five Turkish words was exposed at various frequencies to large numbers of people. Questionnaires containing the test words and a good-bad rating scale for each were subsequently distributed among the school populations. The hypothesis gained support: respondents assigned the highest affective ratings to the most frequently exposed words, the lowest ratings to the least frequently exposed words, and moderate ratings to the words appearing at intermediate frequencies.

Evidence has been accumulating recently which shows that the mere repeated exposure of a stimulus object is a sufficient condition for the enhancement of an individual's attitude toward that object (Harrison, 1968; Zajonc, 1968, 1969). In general, this evidence stems from two sources: On the one hand are correlational studies relating the frequencies observed for a given set of stimuli (words, for example) to the affective ratings assigned to them by Ss. On the other hand are laboratory studies in which stimulus frequencies are experimentally manipulated (Harrison, 1968; Johnson, Thomson, \& Frinke, 1960; Matlin, 1969; Zajonc, 1968). In a typical experiment, $S$ s are shown a series of neutral and novel stimuli, some being seen more often than others. The stimuli employed in the various experiments were Chinese-like characters, Turkish words, and photographs of men's faces. Generally, these stimuli are displayed $0,1,2,5,10$, or 25 times in random order. At the completion of the exposure sequence, the Ss are asked to rate the stimuli on an affective scale, such as GOOD-BAD or LIKE-DISLIKE. The typical finding is that affective ratings increase with the logarithm of frequency of exposure.

The relationship between frequency of exposure and attitude is of primary concern in advertising. However, evidence bearing on this relationship cannot be sought from the experience of the advertising industry. Advertisers seem to accept exposure as a necessary condition for the enhancement of attitude toward a product, but not a sufficient one. While advertising relies on repeated exposure of a product, attractive exposure is invariably employed. The aim of the present study is to determine if mere exposure is a sufficient factor in enhancing attitudes under naturalistic conditions. For this purpose, space was purchased from two university newspapers in which were displayed Turkish words in an unadorned, neutral style. These stimuli were exposed different numbers of times during the course of several weeks. At the completion of the display period, affective ratings of the stimuli were obtained.

\section{MATERIALS}

Chosen as critical stimuli were five Turkish words: KADIRGA, SARICIK, BIWOJNI, NANSOMA, and IKTITAF which in a pretest received the lowest of first-impression ratings of 12 such stimuli. Respectively, they were randomly assigned to appear $1,2,5,10$, and 25 times within a 25-day period in two campus newspapers: The Michigan Daily (University of Michigan) and The Michigan State News (Michigan State University). ${ }^{2}$ The assignment of words to frequency categories was reversed in the latter newspaper. Single words were printed in unadorned column-inch boxes. On some days, only one word was printed; on other days, two or three words appeared. At no time were more than three words shown on a given day. During the exposure period, there was no editorial mention of the stimuli, and readers' queries were met with the reply that the purchaser of the displays wished anonymity.

\section{PROCEDURE}

The same single-page questionnaire was administered to all respondents. It began with an instructional paragraph:

"This questionnaire is part of a larger body of research on linguistics and communication. Listed below are 12 words with which you are not likely to be familiar. We would like you to give us your impression of each of the words. Of course, we realize that you could not reasonably guess exact meanings. It will be sufficient for our purposes, however, if you simply estimate whether a particular word means something 'good' or something "bad.'"

The five test words, imbedded in seven filler words, JANDARA, AFWORBU, ENANWAL, ZABULON, CIVADRA, LOKANTA, and DILIKLI, were listed along the left margin. Associated with each word was a 7-point, good-bad scale. Finally, the respondent was asked to indicate whether he had seen the words, and where. Each respondent remained anonymous.

\section{SUBJECTS}

In all, 1,141 Ss took part in the study. The questionnaires were administered in two ways.

\section{Group Questionnaire}

Within 3 days of the completion of each exposure series, 206 and 74 questionnaires were distributed and collected in undergraduate classes at the University of Michigan and at Michigan State University, respectively.

\section{Mail Questionnaire}

Some 1,000 names each were chosen at random from the directories of the two schools. Approximately $70 \%$ of the names were from student directories, the balance was from faculty-staff directories. Packets containing a questionnaire and a stamped, return-address envelope were mailed to the selected individuals on the day following the last of the exposures. The final return-mail sample included 503 respondents from the University of Michigan and 358 from Michigan State University.

\section{RESULTS AND DISCUSSION}

The analysis of the filler words which were not exposed during the course of the "advertising campaign" revealed no differences between scale responses obtained in the classrooms and those obtained from mailed questionnaires. Also, no differences were found for the filler items between Ss recruited from the University of Michigan and those from Michigan State University. Ss claiming to have seen some of the words previously did not differ in their ratings of the filler items from those claiming not to have seen them. The analysis of the critical items, however, yields strong effects. Figure 1 shows the major findings of

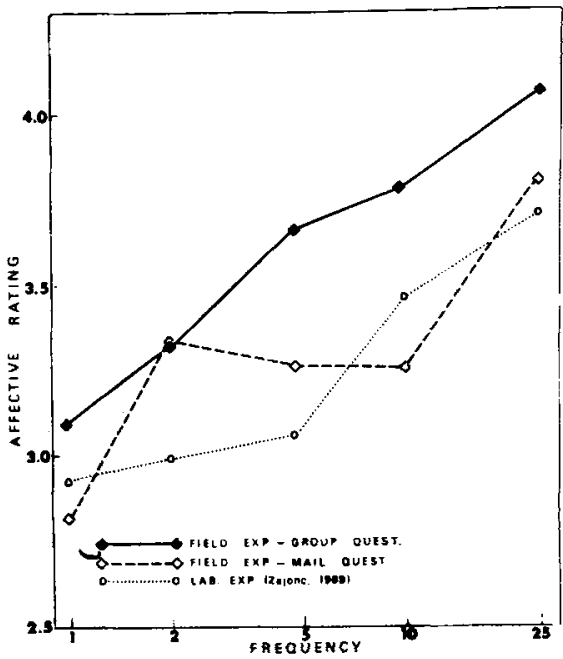

Fig. 1. Average affective ratings of exposed words as a function of frequency of exposure. 
the field experiment for Ss who acknowledged having seen the words. For purposes of comparison, the findings from a previous laboratory experiment are included (Zajonc, 1968). Of main importance is the frequency effect. For Ss claiming to have seen the words $(N=292)$, a simple effects test shows frequency to be a significant factor at the .001 level $(F=15.67)$. Of interest also is the overall main effect contrasting Ss claiming to have encountered the stimuli and those claiming not to have seen them. On the average, the former rated the critical words at 3.35 , while the latter rated them at 3.06 , a difference reliable at the .001 level $(F=35.75)$. For the filler words, which had not been displayed in the newspapers, no such difference was obtained. Additionally, the Ss tested in class did not differ from those polled by mail when the critical words were compared, and there was no interaction between the form of test administration and the frequency of appearance of the critical words. ${ }^{3}$

The above results can be taken as a further confirmation of the effects of mere exposure. It is of interest to note that the results of the field and laboratory experiments are quite similar, both demonstrating a fairly consistent logarithmic relationship between frequency of exposure and affective ratings.

\section{REFERENCES}

HARRISON, A. A. Response competition, frequency, exploratory behavior, and liking. Journal of Personality \& Social Psychology, $1968,9,363-368$

JOHNSON, R. C., THOMSON, C. W., FRINKE, $G$. Word values, word frequency, and visual duration thresholds. Psychological Review, $1960,53,332-342$.

MATLIN, M. A. W. Response competition as a mediating factor in the frequency-affect relationship. Unpublished doctoral dissertation, University of Michigan, 1969.

ZAJONC, R. B. Attitudinal effects of mere exposure. Journal of Personality \& Social Psychology, 1968, 9(Part 2), 1-27.

ZAJONC, R. B. Attraction, affiliation, and attachment. Paper presented at the Symposium on Comparative Social Behavior, Smithsonian Institute, May 1969.

\section{NOTES}

1. This reseatch was supported by NIMH Grant No. MH 12174-04.

2. The authors wish to express thanks to Miss Carol Budrou of The Michigan State News and to Mr. Randy Rissman of The Michigan Daily for their cooperation and assistance.

3. The second author's name and address were also printed on the questionnaires in the event that respondents, especially those reached by mail, desired further information about the study. It is of incidental interest and of some importance that some of the respondents could not resist also rating this author's name which, like the experimental stimuli, is a seven-letter three-syllable word. These ratings were consistently lower than those of the critical words-a further confirmation of the exposure effect since, to the best of our present krowledge, the name was first seen by our Ss when they responded to the questionnaire. It must also be disclosed, not without some chagrin, that the rating the name received was even lower than those assigned to the filler words. In the cause of fairness, the first author's name will be given equal status as nonsense stimulus word in future research.

\section{Classical reaction time and signal rate in a vigilance setting}

\author{
HANS-OLOF LISPER, University of \\ Uppsala, Uppsala, Sweden
}

Four Ss were employed in an experiment to determine if "classical" reaction time would increase over time in an ordinary vigilance setting. Two signal rates were used, one very high and the other low. The result was an increase in reaction time for the high rate and a constant reaction-time level for the low rate. This result was considered to support on inhibition theory of vigilance decrement, an explanation rejected on empirical evidence in vigilance research. The discrepancy between this and ordinary vigilance experiments was considered to be caused by differences in signal strength and as a consequence of the attention demanded.

It has been documented that the level of detection and/or response latency deteriorates as a function of the time of sustained observation (e.g., Buckner \& McGrath, 1963; Frankmann \& Adams, 1962). Signal characteristics in these so-called vigilance experiments have, more or less by definition, been changes in the stimulus situation (signals) which are not reported to $100 \%$. What happens when the signals are made very clear and, accordingly, are reported to $100 \%$ over the entire period of observation? In other words, what will happen to "classical" reaction time (RT) as a function of observation duration?

In experiments on fatigue and driving
(Lisper, 1966; Lisper et al, 1968), in which RT to a 90-dB auditory signal was used to estimate changes in the driver's spare capacity, it was found that RT increased as a function of driving time. These results would predict that "classical" RT would increase even in a laboratory vigilance setting.

In order to test this proposition, a pilot study with two signal rates was performed. Predictions from vigilance research (e.g., Baker, 1963) would suggest that a high signal rate would result in a shorter $\mathrm{RT}$ than a low rate. The pilot study did not confirm this hypothesis, but pointed at a far more interesting tendency, viz, the high signal rate gave a faster RT increase than the low rate over the $3 \mathrm{~h}$. This tendency, being reliable, might in fact revive N. H. Mackworth's (1950) inhibition theory as an explanation of the performance decrement in vigilance research. The experiment reported is thus specifically aimed at investigating this tendency, and the hypothesis is that a high signal rate gives a faster RT increase over time than does a low rate.

\section{METHOD}

Two female and two male students from an introductory psychology class served as Ss. All participated in two experimental sessions of $3 \mathrm{~h}$ each, separated by 1 week. The $S$ 's task was to depress a microswitch as fast as possible each time a 1,000-cps/90-dB signal was heard in the headphones. Reaction time was recorded by a Phillips decade counter and automatically recorded 